\title{
The Effect of Corporate Social Responsibility (CSR) Activities on Companies With Bad Reputations
}

\author{
Yeosun Yoon \\ Ewha Womans University \\ Zeynep Gürhan-Canli \\ Koç University \\ Norbert Schwarz \\ University of Michigan
}

\begin{abstract}
Based on theories of attribution and suspicion, three experiments highlight the mediating role of perceived sincerity of motives in determining the effectiveness of CSR activities. CSR activities improve a company's image when consumers attribute sincere motives, are ineffective when sincerity of motives is ambiguous, and hurt the company's image when motives are perceived as insincere. Variables affecting perceived sincerity include the benefit salience of the cause, the source through which consumers learn about CSR, and the ratio of CSR contributions and CSR-related advertising. High benefit salience of the cause hurts the company, in particular when consumers learn about it from a company source. This backfire effect can be overcome by spending more on CSR activities than on advertising that features CSR.
\end{abstract}

Corporate social responsibility (CSR) activities have been used to address consumers' social concerns, create a favorable corporate image, and develop a positive relationship with consumers and other stakeholders. In the age of Enron and corporate scandals, CSR is becoming increasingly important in the corporate world. In particular, companies with bad reputations (e.g., companies in the tobacco and oil industries) seem to be interested in changing their negative image through CSR activities. However, while some companies (e.g., BP and Shell) successfully changed their image by stressing their environmental and social initiatives, the same strategy has backfired for others (e.g., Monsanto and Exxon; Arnold, 2001). Despite increasing research efforts investigating the effects of CSR on consumers' attitudes, extant research does not explain why consumers respond differently to companies that operate in the same industry and support similar CSR activities. The present research provides a theory-based explanation for the circumstances under which CSR activities may or may not achieve their desired effects in the context of companies with bad reputations.

Correspondence should be addressed to Yeosun Yoon, College of Business Administration, Ewha Womans University, 120-760 Daehyun-Dong 11-1, Seodaemun-Gu Seoul, South Korea.E-mail: yeosunyoon@ewha.ac.kr
CSR activities are consistent with a naive business theory that assumes that consumers will take the activity at face value and attribute positive characteristics to the company, resulting in a more favorable evaluation. This naïve theory dovetails with an extensive body of attribution research that demonstrates a pervasive correspondence bias. In general, social perceivers explain actors' behavior in terms of corresponding traits and dispositions (for a review, see Gilbert \& Malone, 1995): those who do good (bad) things do so because they are good (bad) people. However, perceivers do not make these correspondent trait attributions when they become suspicious of the motives underlying the actor's behavior. As Fein and Hilton (1994; Fein, Hilton, \& Miller, 1990; Hilton, Fein, \& Miller, 1993) demonstrated, suspicious perceivers engage in more complex attributional processing that attenuates or eliminates the usually observed correspondent inference bias. Extending this work to consumer behavior, we specify conditions under which consumers become suspicious of the true motives behind a CSR activity, thus thwarting the company's efforts. When consumers become suspicious and infer that the company's true motive for the CSR activity is only to improve its image, CSR activities are not only inefficient but may actually backfire, leaving the company with a more negative image than would be the case 
without the CSR activity. Indeed, some recent examples (e.g., Avon, Philip Morris, etc.) indicate that CSR campaigns can hurt the company. When Philip Morris started to support a youth smoking prevention campaign, both critics and consumers criticized its CSR campaign (Fairclough, 2002; Landman, Ling, \& Glantz, 2002). This is certainly contrary to what the company had hoped to achieve.

In the following section, we review relevant literature in the area of CSR, attribution, and suspicion. Next we report three experiments that investigate the effects of benefit salience of the cause, the source of CSR information, the ratio of CSR contributions and-CSR related advertising on suspicion, inferred motives, and company evaluations.

\section{THEORETICAL BACKGROUND}

\section{Corporate Social Responsibility}

CSR activities have been adopted based on growing evidence that consumers are willing to give incentives to socially responsible corporations (Brown \& Dacin, 1997; Creyer \& Ross, 1997; Ellen, Mohr, \& Webb, 2000; Murry \& Vogel, 1997; Nelson, 2004; Sen \& Bhattacharya, 2001). For example, consumers are willing to pay higher prices for products made by an ethical company (Creyer \& Ross, 1997), to switch brands to support companies that make donations to nonprofit organizations, and to buy products from a company simply because it supports charitable causes (Smith \& Alcorn, 1991).

Supporting a CSR activity affects not only purchase motives but also evaluations of the company (Sen \& Bhattacharya, 2001). Studies showed, however, that the effect of CSR activities on company evaluations may be moderated by other factors. Ellen, Mohr, and Webb (2000) suggested that consumers react differently to cause-related marketing efforts based on the types of causes a retailer supports. Participants in their study evaluated the retailer more positively when the congruency of the donated product with the retailer's core business was high rather than low. Menon and Kahn (2003) found that higher congruence between the sponsor and the social issue led to favorable ratings for cause promotions when elaboration on the sponsorship activity is facilitated. Similarly, Sen and Bhattacharya (2001) suggested that consumers evaluate the company more favorably when a CSR activity is relevant to the company's existing products. For instance, respondents evaluated a company that manufactures calculators more favorably when it supported fair overseas manufacturing practices rather than women's and minority rights. However, these studies focused on companies whose prior reputations were either positive or neutral. As recent examples cited earlier suggest (e.g., Exxon, Philip Morris), similar results may not be observed when the companies have poor reputations.
Consistent with this reasoning, a few studies examined when a CSR activity may not achieve the intended effects (Forehand \& Grier, 2003; Osterhus, 1997; Strahilevitz, 2003; Webb \& Mohr, 1998). Osterhus (1997) suggested that trust in a company and its position toward the CSR activity affect successful outcomes of a CSR activity. Unless consumers trust the company's pro-social position, they are not willing to reward the company for its CSR activity. Also, Webb and Mohr (1998) reported that some respondents expressed reservations toward a company donating a certain percentage of the sale price to a nonprofit organization or a cause. Strahilevitz (2003) found that CSR activities do not enhance the reputation of companies that are perceived to be unethical. Forehand and Grier (2003) showed that high congruence between the firm and the cause leads to increased salience of firm-serving benefits. This increased salience of firm-serving benefits has a negative impact on company evaluation when the company itself claims public-serving benefits. Forehand and Grier's (2003) research is particularly relevant for companies with poor reputations. For example, donating money to a cancer association (vs. an environmental association) should lead to increased salience of firm- serving benefits for a tobacco company because smoking causes cancer and tobacco companies are interested in changing negative public perceptions in this context. Moreover, fighting cancer is at odds with the health consequences of a tobacco company's main line of business, which is likely to undermine the perceived sincerity of the company's motives.

In sum, previous research suggests that consumers' distrust and skepticism toward the company and its CSR activity may moderate the effectiveness of CSR activity on evaluations. Thus, identifying factors and processes that cause consumers to be skeptical about the company's true motives behind the CSR activity is an important research priority. The following section will discuss the literature on attribution and suspicion to understand when consumers become suspicious about CSR activities, paying attention to how suspicion may change the attribution process, affecting company evaluations.

\section{Attribution and Suspicion}

A large body of attribution research demonstrates a pervasive correspondence bias: When people learn about the behavior of a person about whom they have little prior information, they usually take the behavior at face value and attribute it dispositionally. Such correspondent inferences are obtained even when situational factors are salient and sufficient to explain the behavior (for reviews, see Gilbert \& Jones, 1986; Jones, 1979; Trope, 2000). Although this bias is so pervasive that it has been called the "fundamental attribution error" (Ross 1977), it is more pronounced for negative than for positive behaviors (for a review, see Skowronski \& Carlston, 1989), in particular in the morality domain. This is the case 
because negative behavior violates social norms and expectations, thus rendering it particularly informative: The person has engaged in it despite social pressure to do otherwise, hence the cause of the behavior is probably to be found in the person rather than external social influence forces (e.g., Lingle \& Ostrom, 1979; Pratto \& John, 1991). Positive behavior, on the other hand, tends to arise from social demands and normative pressure, rendering it less diagnostic for the person's underlying dispositions. Moreover, even bad people occasionally do good things, further reducing the informational value of isolated positive behaviors (e.g., Skowronski \& Carlston, 1987; Ybarra \& Stephan, 1996).

Given this ambiguity of positive behavior, people refrain from making correspondent inferences about the actor's positive dispositions whenever they have reason to suspect ulterior motives (Fein et al., 1990; Fein \& Hilton, 1994; Hilton et al., 1993). Empirically, Fein et al. (1990) showed that suspicion triggers more complex and sophisticated attributional reasoning, including the generation of multiple, plausible hypotheses about the motives that drive a person's behavior. This more complex reasoning reduces the likelihood that perceivers fall prey to the fundamental attribution error. These effects of suspicion are consistent with the general observation that people engage in more complex information processing whenever they have reason to doubt the validity of information offered to them (e.g., Schul \& Burnstein, 1990). Finally, information that is at odds with perceivers' expectations about the actor, e.g., because it contradicts what is known about the actor's previous behavior, further increases the likelihood of extensive attributional processing (e.g., Hastie \& Kumar, 1979; Srull, 1981).

In combination, these lines of psychological research suggest that (a) positive behavior (which is less informative than negative behavior to begin with), for which the actor may (b) have ulterior motives, is unlikely to be attributed to the actor's positive dispositions, in particular when such motives are salient. Unfortunately, these variables are likely to apply to many CSR situations, where a corporation engages in (a) a positive behavior in (b) the hope of improving its image to counteract the impact of (c) previous negatively perceived behaviors. Consumers should be particularly reluctant to draw the desired positive inferences the more contextual information provides reasons to suspect ulterior motives, e.g., when the company seems to "brag" with its good deeds in advertising campaigns. Finally, the observation that a company tries to do good in a domain that is negatively affected by its usual business should further increase the suspicion that its motives are not sincere-if they really cared about this cause, they would presumably change their business practice. Under these conditions, CSR activities may be discounted, rendering them ineffective. Worse, it is possible that CSR activities backfire, leaving the company with more negative evaluations than would have been the case without the CSR effort. The present studies address these issues.

\section{EXPERIMENT 1}

\section{Hypotheses}

Companies' motives to engage in CSR activity always include image promotion, and we assume that consumers are aware of this. As Friestad and Wright (1994) noted in their Persuasion Knowledge Model, consumers develop knowledge about companies' marketing strategies and tactics, presumably including CSR. However, companies have a choice with regard to the causes they support and how they convey this information. These choices may, or may not, reflect a sincere interest in the cause (in addition to image-promotional motives). Previous research suggests that consumers assess sincerity in the context of consumer-salesperson interaction (Campbell \& Kirmani, 2000; DeCarlo, 2005). For example, Campbell and Kirmani (2000) found that when ulterior motives were accessible, consumers inferred an underlying persuasion attempt and the target salesperson was perceived as less sincere. We extend these findings to the context of CSR.

As noted earlier, in the context of CSR, the type of cause that the company supports may increase the salience of firm-serving benefits (Forehand \& Grier, 2003). Causes that are related with the company's business should increase the salience of firm-serving benefits. Suppose, for example, that a tobacco company chooses to embark on a CSR activity by supporting either the National Cancer Association or the National Environment and Conservation Association. In either case, consumers are presumably aware that the company has a negative image and hopes to improve it through the CSR activity. But how sincere is the company with regard to the cause chosen? If the beneficiary is the National Cancer Association, the CSR activity is at odds with the negative health effects of the company's core business. Moreover, these negative health effects may become particularly salient in light of this cause. This combination should arouse profound suspicion regarding the sincerity of the company's motives.

If there is other contextual information available, consumers may process it systematically to determine the company's true motives. One relevant piece of information is the source of information (Priester \& Petty, 2003; Szykman, Bloom, \& Blazing, 2004; Tormala \& Petty, 2004). For example, Syzkman et al. (2004) found that consumers who viewed an anti-drinking and driving message sponsored by a beer company (vs. a nonprofit organization) inferred more self-serving motives of the sponsor. Consumers expect to learn about CSR activities through both company sources and unbiased media sources such as editorial coverage on television and in the press (Dawkins, 2004). There are specialty publications such as Business Ethics, or independent organizations that provide relatively unbiased information on corporate social responsibility. If consumers learn from a neutral source that a tobacco company supports the National Cancer Association but does little to advertise this fact, the company's motives 
remain somewhat ambiguous. In this case, consumers may merely discount the CSR activity, maintaining their pre-existing negative evaluation of the company. If the company actively advertises its CSR activity, on the other hand, ulterior motives will certainly be inferred and the company will be perceived as insincere (Campbell \& Kirmani, 2000). Perceptions of low sincerity, in turn, may give rise to backfire effects, resulting in more negative company evaluations than would be the case without CSR activities. This prediction is consistent with the observation that brand evaluations decline when consumers infer manipulative intent from company actions (Campbell, 1995).

Suspicion with regard to the sincerity of the company's motives should be less pronounced, however, when the beneficiary is not related with the company's core business, e.g., the National Environment and Conservation Association in the case of a tobacco company. Although consumers will still be aware that the company has good reason to improve its image, the company's core business does not call the sincerity of its support for environmental causes into question. If consumers learn about this activity from a neutral source, it may be well received and may improve the company's image. On the other hand, if the company is seen as bragging with this information, it will probably be discounted, and consumers may maintain their pre-existing negative evaluation. However, we would not expect a backfire effect of the CSR activity in this case, since perceptions of sincerity are ambiguous rather than very low.

This reasoning results in the following hypotheses:

H1a: When a company supports a CSR activity that has high benefit salience, and consumers learn about the CSR activity through a company source, consumers are likely to evaluate the company more negatively than without the CSR activity.

$\mathrm{H} 1 \mathrm{~b}$ : When a company supports a CSR activity that has high benefit salience, and consumers learn about the CSR activity through a neutral source, consumers are likely to maintain their existing evaluations.

H2a: When a company supports a CSR activity that has low benefit salience, and consumers learn about the CSR activity through a company source, consumers are likely to maintain their existing evaluations.

H2b: When a company supports a CSR activity that has low benefit salience, and consumers learn about the CSR activity through a neutral source, consumers are likely to evaluate the company more positively.

H3a: CSR activities that have high (vs. low) benefit salience result in perceptions of lower sincerity.
H3b: Consumers infer less sincere motives when they learn about CSR activities from a company source rather than a neutral source.

$\mathrm{H} 3 \mathrm{c}$ : The influence of information source on company evaluations is mediated by the inferred sincerity of motives.

H3d: The influence of benefit salience on company evaluations is mediated by the inferred sincerity of motives.

\section{Method}

Participants. One hundred and twenty eight undergraduate students ( 60 males and 68 females) received course credit for their participation in this experiment. They were randomly assigned to conditions in a 2 (benefit salience of CSR activity: high or low) $\times 2$ (information source: company source or unbiased source) between-subjects design with a nonfactorial control group, which received no CSR information.

Procedure. Participants were told that the researchers were interested in consumer perceptions of companies and brands. They were asked for their personal opinions, and told that there were no right or wrong answers. All participants first read brief information about the company. We used a fictitious tobacco company as a company with a bad reputation. Participants were told that the company is a leading cigarette manufacturer company in Belgium. All participants, including those in the control groups, read:

"Zenet Corporation is a leading cigarette manufacturer in Belgium. In 2000, the company marked the highest revenues, income, volume, and market share among its competitors. Their employees range from world-class engineers and researchers to highly trained manufacturing specialists, to experts in sales, marketing, finance, communications, and human resources."

After reading the information about the company, participants in the control group were asked to evaluate the company at this point without further information. Participants in the experimental groups received additional information regarding a CSR activity run by the same company, as well as the source of the CSR information, as described below. Next, they completed the dependent measures at their own pace and were debriefed. They learned that the company was fictitious, and the information they read about the company and the CSR activities was prepared only for research purposes.

\section{Independent Variables}

Benefit salience of CSR activity. Supporting the National Cancer Associations and other cancer-related organizations represents a CSR activity that has high benefit salience, and supporting the National Environment and 
Conservation Association and other environment-related organizations represents a CSR activity that has low benefit salience. All participants in the experimental groups read:

\begin{abstract}
"Zenet Corporation is one of the largest corporate supporters of cancer research and health causes (environmental protection and conservation causes). In 2000, the company supported the National Cancer Association (National Environmental Protection and Conservation Association) and made numerous grants to cancer-related (environmental) organizations to help to fight against cancer (to protect the environment). Also, the company has partnered with various organizations within the cancer (environmental) community to bring attention and additional resources to bear in the fight against cancer (destroying the environment)."
\end{abstract}

Information source. The information about the CSR activity was allegedly provided either by the company or by an unbiased independent source. The corporate advertisement and the Corporate Social Rating Monitor (CSRM), an independent and nonprofit organization that provides unbiased evaluations of corporate activities, were used as the company and an independent source, respectively.

\section{Dependent Variables}

All dependent variables were measured on 7-point scales anchored by 1 and 7 .

Company evaluations. Participants expressed their evaluations of the company on the following scales: "extremely unfavorable" versus "extremely favorable," "extremely negative" versus "extremely positive," "extremely bad" versus "extremely good," and "extremely not likable" versus "extremely likable." These items were averaged to form a company evaluation index $(\alpha=.93)$. We used "extremely" to anchor all of our scales in order to be consistent.

Inferred motives. All inferred motives were measured on scales anchored by "extremely unlikely" versus "extremely likely." Participants indicated inferences about the sincerity of the company's motives for pursuing the CSR activity through responses to the following statements: "Zenet has genuine concerns for cancer and health causes (environmental protection and conservation) when it supported various cancer (environmental) organizations" and "Zenet sincerely cares about consumers' health (environmental protection and conservation) when it supported various cancer (environmental) organizations." These two measures were averaged to form a sincere motive index $(r=.96)$. Participants indicated their inferences about the company's image-promotional motives for pursuing the CSR activity by responding to the following statements: "Zenet tried to make a good image of the company by supporting various cancer organizations (environmental organizations)" and "Zenet tried to improve its existing image by supporting various cancer organizations (environmental organizations)." These two measures were averaged to form an image promotional motive index $(r=.90)$.

Confound check. Participants indicated their level of agreement with two statements concerning the credibility of CSR information. They indicated the degree to which the information they read about Zenet was believable and credible on scales anchored by "extremely unbelievable" and "extremely believable," and "extremely not credible" and "extremely credible." The two measures were averaged to form a credibility index $(r=.73)$.

Order of the dependent variables. First, participants indicated their overall evaluations of the target company. Next they expressed their inferences about the target company's motives for the CSR activity. Finally, confound checks and demographic questions were presented.

\section{Results}

We analyzed the data according to a 2 (benefit salience of CSR activity: high vs. low) $\times 2$ (information source: company source vs. unbiased source) between-subjects design with a nonfactorial control group. No differential effects on the dependent measures were observed with sex and age as covariates.

Confound check. An ANOVA on the message credibility index showed no significant main and interaction effects. Subjects evaluated that the information they read was believable regardless of the information source and the benefit salience of CSR activity $(M=4.83)$.

Company evaluations. An ANOVA on the company evaluation index revealed main effects of benefit salience and information source. As expected, participants evaluated the company more negatively when it supported a cause that has high benefit salience $(M=3.03)$ rather than a cause that has low benefit salience, $M=3.91 ; F(1,127)=22.06, p<.001$. Moreover, they evaluated the company more negatively when they learned about the CSR activity from the company itself $(M=2.92)$ rather than from a neutral source, $M=3.92$; $F(1,127)=21.60, p<.001$.

More importantly, planned contrasts with the nonfactorial control group, which received no information about CSR activities, identified conditions under which CSR is effective, ineffective, or backfires. As expected, learning about a CSR activity that has high benefit salience through the company's advertisements resulted in a backfire effect. In this case, participants evaluated the company more negatively $(M=2.31)$ than when they were unaware of the CSR activity, $M=3.27$; $F(1,127)=8.84, p<.01$. On the other hand, the company's evaluation remained unchanged relative to the control group 
when participants learned about a CSR activity that has high benefit salience through a neutral source, the Corporate Social Rating Monitor, $M=3.45 ; F(1,127)=.24, p>.62$. These findings are consistent with hypotheses 1 (a) and 1(b).

A parallel analysis of CSR effects under conditions where the cause is low in terms of its benefit salience revealed a different pattern. In this case, learning about the CSR activity through the company's own advertising campaign did not affect participants' evaluations $(M=3.46)$ relative to the control group, $M=3.27 ; F(1,127)=.37, p>.54$. However, learning about this activity through the neutral Corporate Social Rating Monitor improved the company's evaluation $(M=4.38)$ relative to the control group, $F(1,127)=12.01, p<.01$. These findings are consistent with the hypotheses 2(a) and 2(b).

Inferred motives. As expected, participants believed that companies had high degrees of image promotional motives $(M=6.55)$, regardless of the benefit salience of CSR activities or the information source. Hence, an ANOVA revealed no main or interaction effects. In contrast, an ANOVA on the sincere motive index revealed main effects of benefit salience and the information source. As predicted, participants perceived the motives as less sincere when the company supported a cause that has high versus low benefit salience, $M=2.43$ vs. $3.06 ; F(1,103)=4.88, p<.05$. Similarly, learning about the activity through the company's advertising resulted in lower perceived sincerity $(M=2.22)$ relative to an unbiased source, $M=3.27 ; F(1,103)=13.45, p<.001$. These findings are consistent with hypotheses $3(a)$ and $3(b)$. Comparisons with the control group were not feasible for this index since the control group did not learn about any (sincere or insincere) CSR activity.

Mediation analyses. To see the extent to which sincere motives mediated the effects of information source on company evaluations, we conducted four sets of regression analyses as suggested by Baron and Kenny (1986). First, we regressed company evaluations on the dummy-coded information source $(0=$ company source and $1=$ neutral source $)$. In the second analysis, we regressed sincere motives on the dummy-coded information source. Third, we regressed company evaluations on sincere motives and the dummy-coded information source. Support for mediation would be obtained if (1) the effect of information source on company evaluation is significant, (2) the effect of information source on sincere motives is significant, and (3) the effect of information source on company evaluations is reduced or eliminated when the mediating variable is entered into the analysis. We found that information source significantly predicted company evaluations $(b=1.01, p<.001)$. The effect of information source on sincere motives was also significant $(b=$ $1.06, p<.01$ ). Importantly, the effect of information source on company evaluations was reduced (from $b=1.01$ to $b=$ $.64, p<.01$ ) when sincere motives were entered into the analysis. Following the statistical test suggested by Baron and
Kenny (1986), we found the indirect effect of information source on company evaluations through sincere motives was significantly different from zero $(z=3.10, p<.001)$, indicating partial mediation. These results are consistent with hypothesis 3(c).

We also conducted a similar mediation analysis to examine the extent to which sincere motives mediated the effect of benefit salience on company evaluations. First, we regressed company evaluations on the dummy-coded benefit salience $(0=$ low and $1=$ high $)$. In the second analysis, we regressed sincere motives on the dummy-coded benefit salience. Third, we regressed company evaluation on sincere motives and the dummy-coded benefit salience. We found that benefit salience significantly predicted company evaluations $(b=1.02$, $p<.001)$. The effect of benefit salience on sincere motives was also significant $(b=.63, p<.05)$. Importantly, the effect of benefit salience on company evaluations was reduced (from $b=1.02$ to $b=.79, \mathrm{p}<.01$ ) when sincere motives were entered into the analysis. Consistent with hypothesis 3(d), the indirect effect of benefit salience on company evaluations through sincere motives was significantly different from zero $(z=3.30, p<.001)$.

\section{Discussion}

The results of the first experiment were consistent with all hypotheses. As expected, consumers assumed that CSR activities were motivated by image-promotional goals under all conditions. However, the benefit salience of the cause, as well as the source through which consumers learned about the CSR activity, determined consumers' perceptions of the sincerity of the company's motives. Consumers attributed the most sincere motives under low benefit salience and when they learned about the CSR activity from a neutral source. Conversely, they attributed the lowest sincerity under high benefit salience and when they learned about the CSR activity through the company's own advertising.

As expected, consumers' evaluations of the company followed the pattern of perceived sincerity of motives. CSR activities only improved company evaluations when sincere motives were attributed, namely, when the company supported a cause that is low in benefit salience and consumers learned about it from a neutral source. Conversely, the CSR activity backfired when consumers had reason to doubt the company's motives, namely, when the company supported a cause with high benefit salience and they learned about it from the company itself. Under this condition, consumers evaluated the company more negatively than without the CSR activity. Consumers' evaluations of the company were unaffected by CSR activities under the remaining conditions, namely, when the CSR activity was low in benefit salience and they learned about it from the company or when it pertained to a cause that was high in benefit salience and they learned about it from a neutral source. Mediation analyses 
confirmed the key role of perceived sincerity in company evaluations.

In combination, this pattern of results suggests that CSR activities are futile, or even counterproductive, unless consumers perceive the activity as driven by a sincere interest in the supported cause.

\section{EXPERIMENT 2}

Experiment 2 provides a replication of these findings based on a different industry and different information sources. Because tobacco companies suffer from a particularly negative, emotionally charged reputation, we replaced the fictitious tobacco company used in Experiment 1 with a real company from the oil industry, namely, Exxon. In addition, we used a newspaper article as the neutral independent source instead of the Corporate Social Rating Monitor used in Experiment 1. These changes allow us to assess the robustness of our previous findings. Finally, we measured the degree of suspicion to provide more direct evidence that suspicion induces consumers to engage in more sophisticated attribution processes. We predicted:

H4a: Suspicion regarding the company's motives is higher when the company supports a cause that has high (vs. low) benefit salience.

H4b: Suspicion is higher when participants learn about the CSR activity through a company source rather than through an unbiased source.

The method and data analyses are similar to those used in Experiment 1.

\section{Method}

Participants. One hundred and twenty four undergraduate students ( 76 males and 48 females) participated in this experiment for course credit. They were randomly assigned to conditions in a 2 (benefit salience of CSR activity: high or low) $\times 2$ (information source: company source or unbiased source) between-subjects design with a nonfactorial control group, which received no CSR information.

Procedure and measures. Participants were told we are interested in consumers' perceptions of companies and brands. They were asked for their personal opinions, and told that there were no right or wrong answers. All participants, including those in the control group, read the following company information:

\footnotetext{
"Exxon is one of the world's leading petroleum and petrochemical companies. In 2001, the company marked the highest revenues, income, volume, and market share worldwide
}

compared to its competitors. Its employees range from world-class engineers and researchers to highly trained manufacturing specialists, to experts in sales, marketing, finance, communications, and human resources. However, its verified greenhouse oil emissions to the air are significantly higher than any other petroleum company's since 1988. Also, the volume of oil spilled in the environment by this company is the highest among the petroleum and petrochemical companies. In sum, the company is considered to be the worst among the petroleum and petrochemical companies in taking environmental responsibility seriously."

Participants in the control group were asked to evaluate the company at this point without further information. In addition to the company information, participants in the experimental groups received information regarding a CSR activity run by the company as well as the source of the CSR information, as described below.

Next, participants completed the dependent measures, which were similar to those used in Experiment 1 except that we included measures of suspicion. First, participants indicated their overall evaluations of the target company. Next, they reported their inferences about the target company's motives for the CSR activity and indicated their level of suspicion regarding the company's true motives. The latter measures asked, "Please indicate the degree to which you were suspicious if Exxon sincerely cared about the cancer and health issues (environmental protection and conservation issues) when it supported various cancer organizations (environmental organizations)" and "Please indicate the degree to which you were suspicious if Exxon had genuine concern for the cancer and health issues (environmental protection and conservation issues) when it supported various cancer organizations (environmental organizations)." The answers were provided along 7-point rating scales ranging from 1 (extremely unsuspicious) to 7 (extremely suspicious). While these measures were somewhat leading in highlighting causes of suspicion, we needed to be explicit about what they were suspicious of. The two measures were highly correlated and were averaged to form a suspicion index $(r=.88)$.

Finally, manipulation checks and demographic questions were presented. After they completed the questionnaire at their own pace, participants were thoroughly debriefed. They were told that the information they read was prepared for research purposes and that the information about Exxon and their social responsibility activities in general are NOT correct.

\section{Independent Variables}

Benefit salience of CSR activity. Supporting the National Environment and Conservation Association represents a CSR activity high in benefit salience, whereas supporting the National Cancer Association represents a CSR activity low in benefit salience. Participants in the experimental groups read: 
"Exxon is one of the largest corporate supporters of environmental protection and conservation activities (cancer research and health-care-related activities) in 2001. The company supported the National Environmental and Conservation Association (National Cancer and Health Association) and made numerous grants to environmental (cancer and health-care-related) organizations to help to protect the environment (to fight against cancer) in 2001. Also, the company has partnered with various organizations that implement environmental programs to bring attention and additional resources to help protect and preserve the earth's resources (various cancer and heath organizations to bring attention and additional resources to bear in the fight against cancer)."

Information source. The information about the CSR activity was attributed either to the company itself and presented as a corporate advertisement or to an unbiased independent source and presented as a newspaper article.

\section{Results}

We analyzed the data using a 2 (benefit salience: high or low) $\times 2$ (information source: company source or unbiased source) between-subjects design with a nonfactorial control group. No differential effects on the dependent measures were observed with sex and age as covariates.

Confound checks. An ANOVA on the message credibility index $(r=.79)$ showed no significant main and interaction effects. Subjects indicated that the information was believable regardless of the information source and benefit salience $(M=4.90)$.

Company evaluations. An ANOVA on the company evaluation index $(\alpha=.95)$ revealed main effects of benefit salience and information source. As in Experiment 1, participants evaluated the company more negatively when it supported a cause that was high $(M=2.55)$ rather than low, $M=$ $4.89 ; F(1,123)=125.53, p<.001$, in benefit salience. Further, they evaluated the company more negatively when they learned about the CSR through the company's advertising campaign $(M=2.79)$ rather than through a newspaper article, $M=4.14 ; F(1,123)=65.49, p<.001$.

More importantly, planned contrasts with the control group again revealed a significant backfire effect. Participants evaluated the company more negatively when it supported a cause that is high in benefit salience and they learned about it from the company itself $(M=2.03)$ than when they never learned about any CSR activity in the first place, $M=$ $3.24 ; F(1,123)=29.28, p<.001$. However, the same CSR activity did not affect company evaluations relative to the control condition when participants learned about it through a newspaper article, $M=3.12 ; F(1,123)=.30, p>.58$. These findings replicate the results of Experiment 1 and are consistent with hypotheses $1(a)$ and $1(b)$.
As in Experiment 1, learning about a CSR activity that is low in benefit salience did not influence company evaluations $(M=3.61)$ relative to the control condition $(M=3.24)$ when participants learned about it through the company itself, $F(1,123)=2.69, p>.10$. Learning about the same activity through an unrelated source, however, improved company evaluations, $M=5.13 ; F(1,123)=69.92, p<.001$. These findings are consistent with hypotheses 2 (a) and 2 (b).

Perceived suspicion. An ANOVA on the suspicion index revealed main effects of benefit salience and information source. Participants were more suspicious when the company supported a cause that was high (vs. low) in benefit salience, $M=6.21$ vs. $5.49 ; F(1,98)=7.39, p<.01$. Participants' suspicion was also higher when they learned about the CSR through a company advertisement $(M=6.11)$ rather than a newspaper article, $M=5.59 ; F(1,98)=7.39, p<.01$. These findings are consistent with hypotheses 4 (a) and 4(b).

Inferred motives. An ANOVA on image promotional motives $(r=.81)$ revealed no main or interaction effects. Regardless of benefit salience or information source, participants indicated that the company had high degrees of image promotional motives $(M=6.57)$. An ANOVA on the sincere motive index $(r=.88)$ revealed main effects of benefit salience and information source. As in Experiment 1, participants attributed less sincere motives when the CSR was high $(M=2.19)$ rather than low, $M=3.64 ; F(1,98)=44.42, p<$ .001 , in benefit salience. Moreover, they attributed less sincere motives when they learned about the CSR through a company advertisement $(M=2.31)$ rather than a newspaper article, $M=3.52 ; F(1,98)=30.15, p<.001$. Comparisons with the control group were not feasible for this index since the control group did not learn about any (sincere or insincere) CSR activity.

Mediation analyses. To see the extent to which sincere motives mediated the effects of information source on company evaluations, we again conducted a similar mediation analysis we used in Experiment 1. First, we regressed company evaluations on the dummy-coded information source $(0=$ company source and $1=$ neutral source $)$. In the second analysis, we regressed sincere motives on the dummy-coded information source. Third, we regressed company evaluations on sincere motives and the dummy-coded information source.

We found that information source significantly predicted company evaluations $(b=1.35, p<.001)$. The effect of information source on sincere motives was also significant $(b=$ $1.21, p<.001)$. Importantly, the effect of information source on company evaluations was reduced (from $b=1.35$ to $b=$ $.66, p<.01$ ) when sincere motives were entered into the analysis. This indirect effect of information source on company evaluations through sincere motives was significantly different from zero $(z=4.49, p<.001)$, suggesting that sincere mo- 
tives partially mediated the effect of information source on company evaluations. These findings are consistent with hypothesis 3(c).

We also conducted a similar mediation analysis to examine the extent to which sincere motives mediated the effect of benefit salience on company evaluations. First, we regressed company evaluations on the dummy-coded benefit salience $(0=$ low and $1=$ high). In the second analysis, we regressed sincere motives on the dummy-coded benefit salience. Third, we regressed company evaluation on sincere motives and the dummy-coded benefit salience. We found that benefit salience significantly predicted company evaluations $(b=1.84$, $p<.001)$. The effect of benefit salience on sincere motives was also significant $(b=1.45, p<.001)$. Importantly, the effect of benefit salience on company evaluations was reduced (from $b=1.84$ to $b=1.17, p<.001$ ) when sincere motives were entered into the analysis. Consistent with hypothesis 3(d), the indirect effect of benefit salience on company evaluations through sincere motives was significantly different from zero $(z=5.13, p<.001)$.

\section{Discussion}

The results of the second experiment replicate the findings of Experiment 1 with different materials and support all hypotheses. In addition, a direct measure of suspicion indicated that consumers were more suspicious about the sincerity of the company's motives when the company supported a CSR activity that is high (vs. low) in benefit salience. Also, they reported higher suspicion when they learned about the CSR activity through a company source than an unbiased source.

As in Experiment 1, the pattern of company evaluations reflected consumers' perceptions of the sincerity of the company's motives. CSR activities only improved company evaluations when sincere motives were attributed, namely, when the company supported a cause that was not high in benefit salience and consumers learned about it from a neutral source. Conversely, the CSR activity backfired when consumers had reason to doubt its motives, namely, when the company supported a cause that was high in benefit salience and they learned about it from the company itself. Under this condition, consumers evaluated the company more negatively than without the CSR activity. Consumers' evaluations of the company were unaffected by CSR activities under the remaining conditions, namely, when the CSR activity pertained to a cause with low benefit salience and they learned about it from the company or when it pertained to a cause with high benefit salience and they learned about it from a neutral source. Mediation analyses confirmed the key role of perceived sincerity in company evaluations.

In sum, the results from Experiment 1 and 2 support our hypotheses about when consumers become suspicious about the sincerity of a company's motives and highlight that perceived sincerity is a crucial prerequisite for a successful CSR campaign. When sincerity is ambiguous in consumers' eyes,
CSR activities are ineffective-and when perceived sincerity is extremely low, CSR activities hurt rather than help the company's image. Experiment 3 explores what companies can do to improve perceptions of their sincerity when they embark on a CSR effort high in benefit salience. In addition, Experiment 3 extends our analyses to companies that enjoy a positive reputation to begin with and addresses another determinant of perceived sincerity, namely, the company's relative spending on the CSR cause and on CSR-related advertising.

\section{EXPERIMENT 3}

Given the importance of perceived sincerity in the success of CSR campaigns, it is important to understand what other variables may influence sincerity perceptions. As seen, learning about CSR through a company source rather than a neutral source hurts perceived sincerity. Extending this observation, we assume that consumers will be particularly suspicious when they learn that the company spends more on advertising its CSR activity than on supporting the CSR cause itself. On the other hand, high spending on the CSR cause and very limited spending on CSR-related advertising may foster attributions of sincerity. If so, a company with a negative reputation may still benefit from supporting a cause that has high benefit salience when the perceived "pain" of supporting the good cause exceeds the self-interested spending on spreading the news about one's good deeds. In fact, Fein et al. (1990) found that participants who had reason to be suspicious of an actor were quite willing to make strong correspondent inferences from the actor's positive behavior if they learned about other information that rendered it unlikely that the actor's behavior was solely driven by ulterior motives.

To provide a strong test of this possibility, we returned to the scenario from Experiment 1 and presented a tobacco company (negative reputation) that supports the National Cancer Association. Depending on conditions, the company spends more on corporate advertising (Adv) featuring the CSR activity than on contributions to the CSR cause itself (low CSR/Adv ratio) or more on CSR than on advertising (high CSR/Adv ratio). Of particular interest is whether a high CSR/Adv ratio is sufficient to avoid a backfire effect.

We also explore if a company that enjoys a positive reputation may nevertheless suffer from backfire effects of its CSR activities when consumers learn that the company spends more on advertising its good behavior than on supporting the CSR cause itself. As an extreme example, consider the experience of Avon, a company famous for supporting breast cancer causes. In 2002, activists criticized Avon because about $40 \%$ of the donor contribution went into advertising, marketing, administration, and logistics costs-not to the charities (Mooney, 2002). The issue became very controversial and eventually undermined Avon's reputation, prompting the company to cancel the Breast Cancer Walk with Avon campaign in 2003. While the Avon case involved 
money donated by others, we assume that an unfavorable CSR/Adv ratio is sufficient to undermine a company's perceived sincerity even when no external donations are involved.

To provide a strong test of the latter possibility, we used a new scenario in which a nicotine patch company (good reputation) supports the National Cancer Association. As per Forehand and Grier (2003), benefit salience should be high in this context, since supporting the National Cancer Association is related to the company's core business, increasing the ease with which consumers can identify firm-serving benefits. A low CSR/Adv coupled with high salience should undermine perceived sincerity, resulting in a backfire effect even for companies that have good reputations.

These conjectures result in the following hypotheses:

H5a: Consumers evaluate a company more positively when CSR/Adv ratio is high (contributions exceed advertising) rather than low (advertising exceeds contributions).

H5b: A high CSR/Adv ratio is sufficient to overcome the backfire effect observed when a company with a bad reputation supports a cause high in benefit salience. That is, consumers evaluate the company more positively when they know about this CSR activity than when they do not.

H5c: A low CSR/Adv ratio leads to a backfire effect when a company with a good reputation supports a cause high in benefit salience. That is, consumers evaluate the company more negatively when they know about this CSR activity than when they do not.

H6a: Consumers attribute more sincere motives to the company when the CSR/Adv ratio is high rather than low.

H6b: Perceived sincerity of motives mediates the effect of CSR/Adv ratio on company evaluations regardless of company reputation.

\section{Method}

Participants. One hundred thirty nine undergraduate students ( 70 males and 69 females) participated in this experiment for course credit. They were randomly assigned to conditions in a 2 (reputation of the company: good or bad) $\times 2$ (CSR/Adv ratio: high vs. low) between-subjects design with two nonfactorial control groups.

Procedure and measures. Participants read the information used in Experiment 1 regarding the objective of the study, company information, and its CSR activity. We used a fictitious tobacco company as a company with a bad reputation and added a fictitious nicotine patch company as a company with a good reputation. Participants in the two-control conditions only read the respective company information and did not learn about CSR activities.

Participants assigned to the experimental conditions further learned that the company supports the National Cancer Association and other cancer-related organizations. In addition, they were told that the information about the CSR activity was from the company's corporate advertising campaign. We focused only on corporate advertising condition because we expected and found backfire effects under corporate advertising in the first two experiments. By using this context, we wanted to provide a stronger test of our predictions (i.e., whether CSR/adv ratio would be sufficient to overcome the backfire effect).

Finally, participants in the high CSR/Adv ratio condition read that the company contributed $\$ 18.3$ million to cancer-related organizations, while spending $\$ 2.1$ million on the CSR-related advertising campaign. In the low CSR/Adv ratio condition, the respective figures were $\$ 18.3$ million for advertising and $\$ 2.1$ million in CSR contributions. To highlight the amount the company spent for on CSR contributions and advertising, two additional tables were provided. One table showed the top 30 companies by corporate advertising expenditures, and the other table showed the top 30 companies by contribution to cancer-related organizations. In the high CSR/Adv condition, the target company was the 4th-largest contributor to cancer-related organizations, while it was ranked 28th on corporate advertising. In the low CSR/Adv condition, the target company was ranked 4 th for corporate advertising and 28 th on contributions to cancer- related organizations. After reading this information, participants completed the dependent variables at their own pace and were debriefed. They learned that the companies were fictitious, and that the information they read about the companies and the CSR activities was prepared only for research purposes.

The dependent variables were similar to those used in Experiment 1. First, participants reported their evaluations of the target company, using the same items as in Experiments 1 and 2 . These items were highly correlated $(\alpha=.92)$ and were averaged to form a company evaluation index. Next, they reported their inferences about the target company's motives for the CSR activity, again using the same items as in the previous studies. Finally, manipulation checks and demographic questions were presented. To check the manipulation of perceived CSR effort, participants rated the perceived effort on a 7-point scale anchored by "extremely not enough" versus "extremely enough."

\section{Results}

We analyzed the data using a 2 (company reputation: good or bad) $\times 2$ (CSR/Adv ratio: high vs. low) between-subjects design with two control groups. No differential effects on the dependent measures were observed with sex and age as covariate. 
Manipulation check. An ANOVA showed that the manipulation of the CSR/Adv ratio was successful. Participants perceived more CSR effort under the high $(M=4.60)$ than low $(M=2.69) \mathrm{CSR} / \mathrm{CA}$ ratio $(F(1,88)=49.93, p<.001)$.

Confound check. An ANOVA on the message credibility index $(r=.87)$ showed no significant main and interaction effects. Participants evaluated the CSR and company information as credible regardless of company reputation and perceived CSR/Adv effort $(M=5.10)$.

Company evaluations. An ANOVA on the company evaluation index revealed main effects of company reputation and CSR/Adv ratio. As expected, participants evaluated the nicotine patch company more favorably $(M=5.65)$ than the tobacco company, $M=3.27 ; F(1,138)=256.95, p<.001$. They also reported more positive evaluations when the CSR contributions exceeded advertising expenses $(M=5.28)$ than vice versa, $M=2.78 ; F(1,138)=85.458, p<.001$, consistent with hypothesis 5(a).

Additional hypotheses were tested with planned contrasts with the respective control groups. Compared to the control group ( $M=3.27$ ), participants evaluated the tobacco company more negatively $(M=1.63)$ after they learned that the company spent more money on CSR-related advertising than on contributions to the CSR cause, i.e., low CSR/Adv ratio; $F(1,138)=32.95, p<.001$. This observation extends the backfire effects observed in the previous studies. Not so, however, when the CSR contributions far exceeded the advertising expenses (high CSR/Adv ratio). In this case, the CSR activity improved company evaluations $(M=4.17)$ relative to the control group, $F(1,138)=7.15, p<.01$. This finding is consistent with hypothesis 5 (b).

Participants also evaluated the nicotine patch company more favorably when the CSR/Adv ratio for its CSR activity was high $(M=6.30)$ relative to the control group, $M=5.65$; $F(1,138)=14.02, p<.001$. Yet the same CSR activity backfired $(M=4.21)$ when participants learned that spending on the advertising campaign exceeded CSR contributions, low CSR/Adv ratio; $F(1,138)=43.09, p<.001$. This finding is consistent with hypothesis $5(\mathrm{c})$. In combination, these findings suggest that spending patterns indicative of high sincerity facilitate CSR success even under otherwise problematic conditions, whereas spending patterns indicative of low sincerity undermine CSR success.

Inferred motives. An ANOVA on the image-promotional motives revealed no main or interaction effects. Regardless of company reputation or CSR/Adv ratio, participants indicated that the companies had high image promotional motives $(M=6.29)$. An ANOVA on the sincere motive index revealed main effects of company reputation and CSR/Adv ratio. Not surprisingly, participants attributed more sincere motives when the company had a good rather than bad reputation, $M=4.24$ vs. $2.58 ; F(1,88)=44.47, p<$
.001 , and when the CSR/CA ratio was high $(M=4.47)$ rather than low, $M=2.19 ; F(1,88)=88.39, p<.001$. This is consistent with hypothesis $6(a)$.

Mediation analyses. We again conducted a series of regression analyses to test the extent to which sincere motives mediated the effect of perceived CSR effort on company evaluations. For each company, we first regressed company evaluations on the dummy-coded perceived CSR effort $(0=$ low CSR/CA and $1=$ high CSR/CA). We conducted our analyses separately for each company because of their differences in terms of their reputation. In the second analysis, we regressed sincere motives on the dummy-coded perceived CSR effort. Third, we regressed company evaluations on sincere motives and the dummy-coded perceived CSR effort.

We found that perceived CSR effort significantly predicted company evaluations ( $b=2.58, p<.001$ for tobacco company and $b=2.13, p<.001$ for nicotine patch company). The effect of perceived CSR effort on sincere motives was also significant $(b=2.11, p<.001$ for tobacco company and $b$ $=2.29, p<.001$ for nicotine patch company). Importantly, the effect of perceived CSR effort on company evaluations was reduced (from $b=2.58$ to $b=1.31, p<.01$ for tobacco company and from $b=2.13$ to $b=1.47, p<.001$ for nicotine patch company) when sincere motives were entered into the analysis. This indirect effect of perceived CSR effort on company evaluations through sincere motives was significantly different from zero $(z=4.22, p<.001$ for tobacco and $z=$ $3.62, p<.001$ for nicotine patch company), suggesting that sincere motives partially mediated the effect of perceived CSR effort on company evaluations. These findings are consistent with hypothesis 6(b).

\section{Discussion}

The present findings highlight that consumers consider the CSR/Adv ratio a crucial piece of information in evaluating the sincerity of a company's motives. Most importantly, we observed that otherwise-obtained backfire effects are overcome when the "pain of giving" far exceeds the effort of spreading the word about one's good deeds. This was even the case under conditions identified as most detrimental to CSR success in the previous experiments: A tobacco company (negative reputation) supported the National Cancer Association (a cause that is high in benefit salience) and consumers learned about this through a company advertisement (biased source). Nevertheless, the CSR activity resulted in the desired improvement in company evaluations when the contributions to the cause far exceeded the advertising expenses. This suggests that allocating more capital to CSR contributions, while minimizing CSR-related marketing expenses, is one possible way to ensure consumers of the sincerity of the motives behind the CSR activity. Unfortunately, this strategy may leave many consumers uninformed about the CSR activity in the first place. 
Conversely, we observed that CSR activities can backfire when consumers are aware that the advertising-related expenses exceed the CSR contributions. This negative effect was obtained even when the company enjoyed a good reputation, as in the case of a nicotine patch company supporting the National Cancer Association. Consumers evaluated the company more negatively when they learned that most of the company's CSR money went into advertising than when they never heard about the company's CSR activity to begin with. In this case, donating $\$ 2.1$ million to the cause (while spending $\$ 18.3$ million on advertising it) was worse than making no donation at all.

\section{GENERAL DISCUSSION}

The present research contributes to our understanding of the effects of corporate social responsibility and highlights the key role of the perceived sincerity of the company's motives in determining the success of CSR campaigns. From an attribution theory perspective, CSR activities are driven by the company's hope that consumers will draw correspondent inferences: Observing that the company supports worthwhile causes, consumers will hopefully attribute positive motives and high ethical standards to the company, thus improving its image. Psychological research suggests, however, that perceivers will not draw these correspondent inferences when they have reason to suspect that the good behavior is mostly driven by ulterior motives (e.g., Fein et al., 1990). Not surprisingly, consumers are aware that companies engage in CSR for image-promotional reasons, as the consistently high level of image-promotion attributions in our experiments indicates. The good news is that this attribution, by itself, is not enough to undermine the success of CSR campaigns. Consumers apparently take image-promotional motives for granted and focus on the next step: Given that the company wants to improve its image by supporting a worthwhile cause, how serious is it about this cause?

CSR campaigns are most successful whenever suspicion is low. Ideally, a company would support a cause that is low in benefit salience, spend more money on contributions than on advertising, and leave it to others to spread the word about its good deeds. In the absence of these ideal conditions, supporting a cause that is low in benefit salience has been found to improve company evaluations, at least when consumers learn about it from a neutral source (Experiments 1 and 2). Moreover, even supporting a cause that is high in benefit salience can be helpful when other variables indicate sincerity, e.g., when the "pain of giving" far exceeds the money spent on spreading the word (Experiment 3 ).

Conversely, CSR campaigns backfire when suspicion is high, resulting in a more negative image than would be the case without any CSR activity. In the worst possible scenario, a company would support a high benefit-salience cause, spend more money on CSR-related advertising than on CSR contributions, and consumers would learn about the activity from the company itself. Unfortunately, not all worst-case features need to be instantiated to produce a backfire effect. Supporting a high benefit-salience cause and having consumers learn about it from a company source was sufficient to produce backfire effects in Experiments 1 and 2. Moreover, a low contribution to advertising ratio was sufficient to elicit a backfire effect even when a company had a positive reputation (Experiment 3 ).

Finally, CSR activities neither improve nor hurt the company's image at intermediate levels of suspicion. Thus, supporting a low benefit-salience cause but having consumers learn about it from a neutral source did not affect company evaluations in Experiments 1 and 2, limiting the damage to the resources spent on an ineffective campaign.

In combination, these results highlight the important role of suspicion and perceived sincerity of the company's motives. Their overall pattern is incompatible with simpler accounts, like the assumption that CSR efforts are futile when a company has low credibility to begin with. While low credibility fosters suspicion and discredits the company as a source of information about its own good deeds, these hurdles can be overcome when consumers learn about the CSR efforts through a neutral source and the company's CSR/Adv ratio is high.

\section{Future Research}

The present studies were designed to test theoretically derived predictions. To do so, we used strong operationalizations of the key variables, thus increasing the likelihood that we would see the expected effects if they existed (and could move on if we didn't obtain them). While we modeled our scenarios after real-world cases (like Philip Morris' support of a youth antismoking campaign or the critique of Avon's unfortunate contribution to advertising ratio), we acknowledge that the variables associated with CSR activities are often less clear-cut in the market place than in our scenarios. Future research may fruitfully explore the limits of our findings by using multiple levels of the key variables identified in the present studies.

Moreover, our studies focused on identifying the effects of benefit salience, source of information, and perceived CSR effort with limited attention to their relative contributions and likely interaction effects. Consistent with the results of Experiment 3, we propose that the CSR/Adv ratio sends the clearest signal to consumers. Most notably, we found that a high CSR/Adv ratio could overcome backfire effects even when the company had a bad reputation, the benefit salience was high, and consumers learned about the CSR activity from a company source. This suggests that information about the CSR/Adv ratio may override the impact of other variables, which deserves further testing. Of particular interest is the specific contribution-to- advertising ratio that is required to ensure that consumers perceive the company's CSR motives as sincere. We conjecture that high 
perceived sincerity requires that the CSR expenses far exceed the advertising expenses, and the more so, the more other variables call the company's sincerity into question. Future research may fruitfully explore which CSR/Adv ratios provide an adequate balance of doing good and telling consumers about it.

Future research should also explore the generalizability of our findings to companies with good reputations. For example, Ben \& Jerry has an excellent reputation in terms of CSR. Does it hurt the reputation of such companies when they support causes with high benefit salience and advertise their CSR efforts heavily? We conjecture that companies with a good reputation can afford a lower CSR/Adv ratio, but presumably only up to a (to be determined) point.

In addition, the rich body of attribution research in the psychological literature (for a review, see Ross \& Fletcher, 1985) may be fruitfully exploited to identify other variables likely to influence a company's perceived sincerity. As Weiner (2000; see also Folkes, 1988) noted, attribution theory has been underutilized by consumer researchers, despite its high relevance to consumer behavior. Consumers' attributions are also partially a function of individual difference variables, as Sen and Bhattacharya (2001) observed in their analysis of the mediating role of consumers' perceptions of the congruence between their own character and the company's character in the context of CSR. Such analyses may allow companies to tailor CSR activities to their core market segments. Finally, cross-cultural research suggests that attribution processes differ across cultures (for a review, see Choi, Nisbett, \& Norenzayan, 1999). For example, consumers in East Asian cultures tend toprocess information more holistically (vs. analytically), and are more likely to take contextual information into account than consumers in Western cultures. It is conceivable that these differences in processing style render variables like information source differentially influential across cultures, with potentially important implications for global CSR campaigns. In addition, recent research highlights the impact of masculinity or femininity of culture on consumer responses to charity advertising (Nelson, Brunel, Supphellen, \& Manchanda, 2006). Investigating the implications of global CSR campaigns from the perspective of masculinity and femininity of a culture should be fruitful.

CSR activities can help companies improve their image and can make a real difference by contributing to worthy societal causes. Further understanding of the psychological processes that underlie consumers' reactions to CSR activities should help companies to allocate their resources more efficiently and effectively to achieve both goals.

\section{ACKNOWLEDGMENTS}

This research is based on the first author's dissertation. We would like to thank Aronte Bennett and Swati Bhargava for their comments on the manuscript.

\section{REFERENCES}

Arnold, M. (2001, July 12). Walking the ethical tightrope. Marketing, 17.

Baron, R. M., \& Kenny, D. A. (1986). The moderator-mediator variable distinction in social psychological research: Conceptual, strategic, and statistical considerations. Journal of Personality and Social Psychology, 51, $1173-1182$.

Brown, T. J., \& Dacin, P. A. (1997). The company and the product: Corporate associations and consumer product responses. Journal of Markefing, $61,68-84$.

Campbell, M. C. (1995). When attention-getting advertising tactics elicit consumer inferences of manipulative intent: The importance of balancing benefits and investments. Journal of Consumer Psychology, 4, 225-254.

Campbell, M. C., \& Kirmani, A. (2000). Consumers' use of persuasion knowledge: The effects of accessibility and cognitive capacity on perceptions of an influence agent. Journal of Consumer Research, 27, $69-83$.

Choi, I., Nisbett R. E., \& Norenzayan, A. (1999). Causal attribution across cultures: Variation and universality. Psychological Bulletin, 125, 47-63.

Creyer, E. H., \& Ross, W. T. (1997). The influence of firm behavior of purchase motive: Do consumers really care about business ethics? Journal of Consumer Marketing, 14, 421-432.

Dawkins, J. (2004). Corporate responsibility: The communication challenge. Journal of Communication Management, 9, 108-119.

DeCarlo, T. E. (2005). The effects of sales message and suspicion of ulterior motives on salesperson evaluation. Journal of Consumer Psychology, 15, 238-249.

Ellen, P. S., Mohr L. A., \& Webb, D. J. (2000). Charitable programs and the retailer: Do they mix? Journal of Retailing, 76, 393-406.

Fairclough, G. (2002, May 29). Study slams Philip Morris ads telling teens not to smoke-How a market researcher who dedicated years to cigarette sales came to create antismoking ads. Wall Street Joumal (Eastern Edition), p. 1.

Fein, S., \& Hilton, J. L. (1994). Judging others in the shadow of suspicion. Motivation and Emotion, 18, 167-198.

Fein, S., Hilton, J. L., \& Miller, D. T. (1990). Suspicion of ulterior motivation and the correspondence bias. Journal of Personality and Social Psychology, 58, 753-764.

Folkes, V.S. (1988). Recent attribution research in consumer behavior: A review and new directions. Journal of Consumer Research, 14, 548-565.

Forehand, M. R., \& Grier, S. (2003). When honesty is the best policy? The effect of stated company intent on consumer skepticism. Journal of Consumer Psychology, 13, 349-356.

Friestad, M., \& Wright, P. (1994). The persuasion knowledge model: How people cope with persuasion attempts. Journal of Consumer Research, 21, $1-31$.

Gilbert, D. T., \& Jones, E. E. (1986). Perceiver-induced constraint: Interpretations of self-generated reality. Joumal of Personality and Social Psychology, 50, 269-280.

Gilbert, D. T., \& Malone, P. S. (1995). The correspondence bias. Psychological Bulletin, 117, 21-38.

Hastie, R., \& Kumar, P. A. (1979). Person memory: Personality traits as organizing principles in memory for behavior. Journal of Personality and Social Psychology, 37, 25-38.

Hilton, J. L., Fein, S., \& Miller, D. T. (1993). Suspicion and dispositional inference, Personality and Social Psychology Bulletin, 19, 501-512.

Jones, E. E. (1979). The rocky road from acts to dispositions. American Psychologist, 34, 107-117.

Landman, A., Ling, P. M., \& Glantz, S. A. (2002). Tobacco industry youth smoking prevention programs: Protecting the industry and hurting tobacco control. American Journal of Public Health, 92, 917-930.

Lingle, J. H., \& Ostrom, T. M. (1979). Retrieval selectivity in memory-based impression judgments. Journal of Personality and Social Psychology; 37 , 180-194. 
Menon, S., \& Kahn, B. E. (2003). Corporate sponsorships of philanthropic activities: When do they impact perception of sponsor brand? Journal of Consumer Psychology, 13, 316-327.

Mooney, J. (2002, August 2). Avon to stop breast cancer walks. The Denver Post, p. B1.

Murry, K. B., \& Vogel, C. M. (1997). Using a hierarchy of effects approach to gauge the effectiveness of CSR to general goodwill towards the firm: Financial versus nonfinancial impacts. Journal of Business Research, 38, 141-159.

Nelson, K. A. (2004). Consumer decision making and image theory: Understanding value-laden decisions. Journal of Consumer Psychology, 13, 316-327.

Nelson, M. R., Brunel, F. F., Supphellen, M., \& Manchanda, R. V. (2006). Effects of culture, gender, and moral obligations on responses to charity advertising across masculine and feminine cultures. Journal of Consumer Psychology, 16, 45-56.

Osterhus, T. L. (1997). Pro-social consumer influence strategies: When and how do they work? Journal of Marketing, 61, 16-29.

Pratto, F., \& John, O. P. ( 1991). Automatic vigilance: The attention-grabbing power of negative social information. Journal of Personality and Social Psychology, 61, 380-391.

Priester, J. R., \& Petty, R. E. (2003). The influence of spokesperson trustworthiness on message elaboration, attitude strength, and advertising effectiveness. Journal of Consumer Psychology, 13, 408-421.

Ross, L. (1977). The intuitive psychologist and his shortcomings: Distortions in the attribution process. In L. Berkowitz (Ed.), Advances in experimental social psychology (Vol. 10, pp. 173-220). New York: Academic.

Ross, M., \& Fletcher, G. J. O. (1985). Attribution and social perception. In G. Lindzey \& E. Aronson (Eds.), The handbook of social psychology (3rd ed., Vol. 2, pp. 73-122). New York: Random House.

Sen, S., \& Bhattacharya, C. B. (2001). Does doing good always lead to doing better? Consumer reactions to corporate social responsibility. Joumal of Marketing Research, 38, 225-243.
Schul, Y., \& Burnstein, E. (1990). Judging the typicality of an instance: Should the category be accessed first? Journal of Personality and Social Psychology, 58, 964-974.

Skowronski, J. J., \& Carlston, D. E. (1989). Negativity and extremity biases in impression formation: A review of explanation. Psychological Bulletin, 105, 131-142.

Smith, S. M., \& Alcorn, D. S. (1991). Cause marketing: A new direction in the marketing of corporate social responsibility. Journal of Consumer Marketing, 8, 19-35.

Srull, T. K. (1981). Person memory: Some tests of associative storage and retrieval models. Joumal of Experimental Psychology: Human Learning and Memory, 7, 440-463.

Strahilevitz, M. (2003). The effects of prior impressions of a firm's ethics on the success of a cause-related marketing campaign: Do the good look better while the bad look worse? Joumal of Nonprofit and Public Sector Marketing, 11, 77-92.

Szykman, L. R., Bloom, P. N., \& Blazing J. (2004). Does corporate sponsorship of a socially- oriented message make a difference? An investigation of the effects of sponsorship identity on responses to an anti-drinking and driving message. Journal of Consumer Psychology, 14, 13-20.

Tormala, Z. L., \& Petty, R. E. (2004). Source credibility and attitude certainty: A metacognitive analysis of resistance to persuasion. Journal of Consumer Psychology, 14, 427-442.

Trope, Y. (2000). Processing alternative explanations of behavior correction or integration. Journal of Personality and Social Psychology, 79, 344-354.

Webb, D. J., \& Mohr, L. A. (1998). A typology of consumer responses to cause-related marketing: From skeptics to socially concerned. Journal of Public Policy \& Marketing, 17, 226-238.

Weiner, B. (2000). Attributional thoughts about consumer behavior. Journal of Consumer Research, 27, 382-387.

Ybarra, O., and Stephan, W. G. (1996). Misanthropic person memory. Journal of Personality and Social Psychology, 70, 691-700. 